\title{
La generación de recambio político y la nueva sociedad civil: ¿Quién lidera a quién?
}

\author{
Giselle Davis Toledo ${ }^{1}$
}

Universidad de Talca, Talca, Chile. Email: gdavis@utalca.cl

\begin{abstract}
Resumen: La crisis de representatividad de los partidos políticos de centro izquierda cuestiona la calidad de la democracia chilena y la proyección de los mismos. No obstante, constituyen referentes sociohistóricos con capacidad de adaptación a los cambios sociales y tendencias de época. Nos interesó conocer cual es el potencial de la generación de relevo de los partidos políticos de adaptarse a los cambios sociales y de representar a la nueva sociedad civil a partir del estudio de su condición generacional dentro de campo político partidista. Los resultados indican que la condición intergeneracional, la visión heterocrítica frente a las formas de reproducción del poder político y la necesidad de legitimidad social favorecen la comprensión de formas distintas de hacer política que lo acercan a la nueva sociedad civil. Las prácticas políticas distintivas identificadas se asocian a la democracia de audiencia, la transversalidad de las alianzas y del territorio. giones.

Palabras clave: generación, prácticas sociales, partidos políticos, re-
\end{abstract}

\section{The generation of political turnover and the new civil society: Who is leading whom?}

\begin{abstract}
The crisis of representation of the center-left political parties questions the quality of Chilean democracy and its ability to lead the new civil society. In this context, we were interested to know the potential of the next generation of leaders of political parties to adapt to social changes and their visions on this issues. The study analyzes the new generational partisan status in the political arena and their social practices with new civil society. The results indicate that the generation on study is in better position to understand trends and logics of the new civil society because of: 1) their generational condition, 2) their critical view of traditional forms of political parties power reproduction and, 3) their own need of social legitimacy. The distinctive political practices identified are associated to the the emergence of audience democracy, plural partnerships and the mainstreaming of territory.
\end{abstract}

Key words: generation, social practices, political parties, regions.

\section{A geração de recambio política ea nova sociedade civil: Quem está conduzindo quem?}

Resumo: A crise da representação dos partidos políticos de centro-esquerda questiona a qualidade da democracia chilena e sua capacidade de liderança da 
nova sociedade civil. Neste contexto, estávamos interessados em saber o potencial da próxima geração de líderes de partidos políticos para se adaptarem às mudanças sociais e cambios epocales. O estudo analisa o potencial das novas gerações partidárias na arena política e suas práticas sociais com a sociedade civil nova. Os resultados indicam que a geração em estudo está em melhor posição para compreender as tendências e lógica da nova sociedade civil, porque: 1) a sua condição geracional, 2) a sua visão crítica das formas tradicionais de reprodução do poder político e, 3) a sua própria necessidade de legitimidade social. As distintas práticas políticas associadas à nova geração em estudo indicam a emergência da democracia da audiência, as parcerias transversais e plurais ea integração do território.

Palavras-chave: geração, práticas sociais, partidos políticos, regiões.

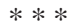

\section{Introducción}

Nos encontramos en un siglo marcado por el surgimiento de nuevos actores civiles de la misma forma que lo estuvo, el siglo anterior por el estado. La modernización del estado y la legitimidad de la gobernabilidad democrática dependen de la capacidad del sistema político de gobierno de conjugar de la representación de los partidos políticos y los intereses ciudadanos en los diferentes territorios. En este escenario, el rol del gubernamental es proveer la institucionalidad y, el de los partidos políticos - orientados hacia el control del gobierno - de actuar como intermediarios entre la sociedad civil y el estado (Giddens 1982). La sociedad civil, es concebida como el conjunto de actores sociales asociados para promover cambios favorables en diferentes niveles territoriales (Habermas, 1988; 1986; 1992). Se le encomienda la representación de las demandas sociales, y la regulación del gobierno y del mercado, constituyéndose así en una tercera fuente de legitimidad y poder social judicial (Rosanvallón, 2006; 2008).

De la capacidad del liderazgo público para equilibrar la regulación social (sobre todo hacia los sectores más vulnerables) y la búsqueda de legitimidad a través de una real participación social depende el éxito de la democracia (Bherer, 2010). Una buena gobernanza civil implica la articulación espontánea de los colectivos y las prácticas sociales que modelan los estilos y tendencias en el manejo del poder desde los sistemas políticos institucionales. Es decir: decidir, ejecutar y evaluar decisiones sobre asuntos de interés público, en un proceso donde el juego de poder - competencia y cooperación - coexisten como reglas consensuadas y posibles de realización (Whittingham, 2002:6).

El Estado de Chile y los partidos políticos, pese a las altas expectativas de la formula democracia representativa social han demostrado durante la última década una débil capacidad de conducción de la ciudadanía organizada. Contrariamente, la fórmula no da los resultados esperados, la institucionalidad público estatal y los partidos políticos carecen de la legitimidad y confianza de sus ciudadanos (OCDE, 2009:35). A la democracia 
chilena se le cuestiona su representatividad y la calidad de los mecanismos de vinculación entre el estado, los partidos políticos y la ciudanía que le otorgan sentido identitario, calidad y proyección a democracia (Ídem).

Desde una visión crítica se plantea, que la democracia y la participación social son constructos declarativos de época sin asidero político institucional en las estrategias de desarrollo. El rol asignado desde gobierno a la ciudadanía sería instrumental, orientado al orden social y a la transferencia a la responsabilidad individual del costo de las decisiones en materia de políticas sociales (Bherer, 2010; Mascareño, 2009:2). Encuadre, que en la práctica excluye proyectos alternativos de sociedad (Zemelman, 1992; Rawls, 1971). La promoción de la autonomía individual y familiar, por sobre la obligatoriedad jurídica y los derechos universales tensiona el empoderamiento social y la legitimación de la democracia. El estado y los partidos políticos oponen resistencia a la participación social en tanto amenaza el control político, “desde arriba” (Mardones, 2006; Eaton, 2004ab; O`Neill, 2005; 2003; Tironi, 1987; 1997; 1999ab; Boeninger, 1993-1998; Otano, 1995; Cavallo, 1992-1998).

Consecuentemente, la ciudadanía se distancia del estado y de los partidos políticos, particularmente aquel sector conformado por las nuevas generaciones quienes adoptan posiciones antagónicas a ambos. La tensión entre el estado y los movimientos sociales son necesarios en el entendido que hace parte de su rol regulador, no obstante preocupa el distanciamiento progresivo entre estos últimos y los partidos políticos, o lo que se identifica en la literatura como la crisis de representatividad de los mismos (Serani, 2006; Arellano \& Bravo, 2006; Garretón, 2010; Siavelis, 1997; 2004 ). Las tensiones internas entre los jóvenes militantes líderes del movimiento estudiantil y sus bases sociales dan cuenta de la importante resistencia a se está generando hacia la conducción de los partidos políticos. Nos encontramos frente a una generación que busca referentes fuera de toda forma de institucionalización del poder lo que si bien significa, una oportunidad de renovación de la política acarrea también el riesgo de polarización ideológica, caudillismo e ingobernabilidad civil. En este escenario, deviene fundamental que los partidos se replanteen la búsqueda de legitimidad social frente a la nueva generación de ciudadanos que participa en los movimientos medio ambientalistas, regionalistas y estudiantiles que ha convulsionado el escenario nacional durante los últimos años (Bherer, 2010: 288).

El problema de representatividad social aludido atañe sobre todo a la Concertación de Partidos por la democracia (Concertación) cuyos partidos - tras dos décadas continuas de gobierno- han priorizado la reproducción del poder político al interior de sus propios campos partidistas en desmedro de la búsqueda de legitimidad social. Estos antecedentes despertaron nuestro interés de comprender, a saber. ¿Cómo se plantean las nuevas generaciones de militantes frente a la crisis de representatividad de los partidos políticos?, ¿Qué cambios requiere el campo político para superar la crisis? y ¿Cuál es su potencial de representación de la nueva sociedad civil? El supuesto que guío el análisis es que la generación de relevo com- 
parte con las nuevas generaciones lógicas y prácticas políticas que los distingue de las elites partidistas y le confiere potencial de representación social. El mayor interés del estudio es aportar pistas para la renovación de los partidos políticos a fin de contribuir a la profundización de la democracia.

La estrategia metodológica cualitativa del estudio analizó desde la perspectiva estructural constructivista (Bourdieu, 1980; 1994; 2000; 2001) y la Teoría Fundamentada (Glaser \& Strauss 1967; Strauss, 1987; Strauss \& Corbin 1990), un corpus empírico de 22 entrevistas semi estructuradas a autoridades regionales militantes de partidos políticos y 38 a líderes de los movimientos sociales, - particularmente del movimiento estudiantil de la Región del Maule- durante los años 2008-2012. Se orientó el análisis hacia la comprensión de las prácticas sociales en la vinculación entre la generación de relevo y los líderes de los movimientos sociales. Los principios de saturación empírica y triangulación por técnicas e informantes le confieren validez interna a los resultados.

El artículo se organiza en tres secciones. En la primera, analizamos la posición de la generación de relevo en el campo político partidista y su condición generacional (Bourdieu, 2000). Referimos a las condiciones sociales e históricas que determinan el encerramiento de la Concertación y a la visión de la generación de relevo sobre el fenómeno. En un segundo momento, abordamos el problema de la crisis de representatividad de la Concertación comparando las visiones de la generación de relevo y de la elite. Finalmente, analizamos la dinámica que se establece entre la nueva sociedad civil y la generación de relevo deteniéndonos en tres dimensiones que la caracterizan, a saber: la mediatización de las causas; la transversalidad política y el territorio. Concluimos, reflexionado sobre las condiciones que favorecerían la representación de la generación de relevo de la nueva sociedad civil y la necesidad de re significar el constructo de “democracia”.

\section{El campo partidista y la generación del medio}

En lo que sigue, analizamos la condición generacional de la generación de relevo y su posición dentro del campo político partidista.

Entendemos la noción de campo político desde la perspectiva estructural constructivista, como un "microcosmos" controlado por un pequeño grupo de personas que reúne ciertas condiciones sociales - educación, tiempo libre, acceso a la información- (Bourdieu, 2000). Desde la visión de Bourdieu, la investidura para acceder al campo es el mandato de representación ciudadana y el prestigio, el principal capital de sus miembros. Los políticos deben cumplir con ciertas reglas del juego - principios y acciones permitidas y prohibidas, o “cultura política” - que permiten la reproducción, regulación y establece los límites del campo. Sus miembros priorizan la reproducción del campo por sobre la representación de sus electores (Ídem). 
La distribución del poder en el campo depende del capital político acumulado, -condiciones y posición dentro del campo de cada miembropor el cual sus miembros. Las generaciones con carreras en proceso de consolidación se encuentran en desventaja frente los fundadores detentores de un importante capital político acumulado. La generación en estudio corresponde a los "recién llegados" pero cuentan, en la mayoría de los casos con un capital heredado que facilita su posicionamiento pues se vinculan a familias de las elites partidarias y/o dirigentes sociales locales² (Ídem). La generación de relevo político milita en los partidos de la Concertación de Partidos por la Democracia (la Concertación) - Socialista, Radical, Demócrata Cristiano, Izquierda Cristiana, Juntos Podemos y Partido por la Democracia-. Todos ellos: ocupan cargos directivos, en las juventudes y/o en sus partidos políticos, a nivel provincial y comunal; son Consejeros Regionales; funcionarios del Gobierno Regional y o comunal (mandos medios) o concejales.

El grupo en estudio, constituye una generación ${ }^{3}$, es decir, un colectivo de individuos de rangos etarios similares, socializados en contextos socio culturales cercanos que condicionan un sentido de pertenencia y "manera de ser en el mundo" que los distingue de otras generaciones (Manheim, [1928]; Ortega y Gasset, [1923-1933]). De acuerdo a esta definición la edad biológica es secundaria para la comprensión del fenómeno. De hecho, las edades de la generación de relevo fluctúan entre los veinticinco y cuarenta años de edad, variación etaria asociada al extenso del itinerario que deben recorrer los políticos para consolidar sus carreras ${ }^{4}$. La generación en estudio hace parte de la clase media y en menor medida de la clase media baja regional, son mayoritariamente varones técnico-profesionales provenientes de familias que los socializaron tempranamente en la política. En general su experiencia como dirigentes y/o como miembros del Gobierno Regional no sobre pasa los siete años. Los antecedentes biográficos del grupo en estudio da cuenta que de formaron en contextos socioeconómicos cercanos: el territorio, género, clase social, niveles educacionales; inserción laboral y socialización política partidista.

En la conformación de una generación se superponen propiedades y tendencias del pensamiento social de época supeditadas a la vez a las estructuras socio económicas. Lo anterior no implica un determinismo generacional sino más bien, un abanico de posibilidades a los cuales accede cada individuo de acuerdo a sus determinantes sociales, biográfica genealógica e itinerario identitario. La construcción de la identidad generacional implica un posicionamiento y re interpretación del sujeto de los factores anteriores que resulta en una subjetividad compartida por el colectivo. El sujeto puede definir su identidad continuando con el legado generacional, posicionándose de manera rupturista frente al mismo o creando referentes alternativos. Si bien, el continuo de posibilidades entre cada opción es indeterminado y tan variado como las trayectorias individuales no es menos cierto que confluyen - en la medida que sus contextos y experiencias sociales se acercan - en un sentido de vida y proyectos que los distinguen de sus coetáneos (Ranciére, 2006). Los proyectos identitarios de la 
generación en estudio se adscriben a los idearios políticos familiares y al ordenamiento del campo político de la "vieja guardia"- fundadores de la Concertación-. Son personas con altas expectativas de logro que proyectan consolidar sus carreras partidistas proyectándose así - frente al inminente envejecimiento de la clase política chilena - como la generación de recambio partidista. No obstante, esta continuidad respecto a las generaciones anteriores es relativizada por una visión hetero crítica frente a sus partidos que analizaremos más adelante.

Comparamos la condición intergeneracional de la generación de relevo con la noción antropológica de etclase, referida a quienes se sitúan en el medio de dos generaciones ${ }^{5}$. La etclase experimenta un vacío generacional, son generaciones que se mueven en "un espacio de nadie" y cuyos proyectos identatarios ambiguos no los demarcan de sus antecesores.

La generación aludida se sitúa en entre la generación decisiva ${ }^{6}$ y los llamados pingüinos. Son descendientes de la primera -militantes de izquierda y centro, agrupados en la Concertación de Partidos por la Democracia- que gobernó el país durante veinte años (1989-2010). La generación decisiva fue parte de los principales hitos de la reciente historia política del país, a saber: la polarización ideológica del gobierno socialista del Salvador Allende; el Golpe de Militar; la represión de la dictadura militar y la transición a la democracia. Si bien, la generación de relevo se formó en este colectivo y representan su continuidad les fue bloqueado hasta la fecha el acceso al poder político (Serani, 2006; Arellano \& Bravo 2006; Leccardi \& Feixa 2010). La generación de relevo compite entonces dentro del campo político cerrado por una clase política que forjó una fuerte identidad en los eventos históricos señalados y protagonizó un proyecto de sociedad y de cambio social.

El grupo más joven de la generación de relevo, nació entre en las décadas de los setenta y ochenta, son los llamados "hijos de la dictadura" es decir aquella generación caracterizada como pasiva, formada en el auge de la sociedad individualista de mercado y sin modelos de participación política democrática. Es la generación que ni siquiera fue silenciada, ya que muchos no habían nacido durante la represión política de la dictadura militar, tampoco fueron protagonistas del retorno a la democracia ya que eran aún demasiado jóvenes, ni participaron en el movimiento estudiantil ya que concluyeron sus estudios superiores. Si bien, los mayores - rodean la cuarentena- en su temprana juventud tuvieron la oportunidad de participar en los grandes movimientos sociales contra la dictadura sin embargo, de adultos fueron formados en el segundo acallamiento social del país, - el silencio social del consenso-. Participaron de dinámicas partidistas cerradas al pluralismo ideológico - dada la frágil estabilidad democrática- y distante del tejido social. Paradojalmente, la participación ciudadana en lugar de fortalecerse en democracia pareció haber perdido el rumbo y se contrajo. La generación de relevo no tuvo experiencia de protagonismo político ni comparte los eventos vitales que le otorgaron identidad y poder a los fundadores de la Concertación. 
Sus predecesores, los pingüinos - 15 y 25 años - y líderes de los movimientos ambientalistas y regionalistas que convulsionan hoy a la sociedad chilena - se identifican a sí mismos como la "generación sin miedo" y la "generación "activa", para diferenciarse de sus abuelos y padres, respectivamente. Esta generación al igual que el anterior, se encuentra unido por experiencias vitales fundantes, los une de igual modo su resistencia al partidismo que asocian con autoritarismo y menoscabo de la autonomía de los movimientos sociales que protagonizan. Se asocian a la nueva sociedad civil y representan un potencial base de apoyo social para la generación de relevo sobre todo, en el contexto de la reciente ley de inscripción automática a los registros electorales.

En resumen, el itinerario biográfico de la generación de relevo es condicionado por circunstancias históricas que la sitúan entre dos generaciones fuertes - protagonistas de cambios sociales- y políticamente cerradas, sin lograr demarcárseles.

\section{La generación de relevo y el encerramiento partidista}

De acuerdo a la teoría de los campos mientras más institucionalizado /formalizado se encuentra un campo político deviene más autónomo, profesionalizado y excluyente. Las circunstancias históricas en que se formó la elite de la Concertación favorecieron el encerramiento del campo. De los veinte años en el poder resultó una importante institucionalización de los partidos políticos y de sus prácticas, situación favorecida por los enclaves autoritarios ${ }^{7}$ de la transición democrática que obstaculizaban la plena representatividad cívica. Si bien la dinámica de negociación y consenso entre conglomerados políticos que excluían la disidencia ideológica contribuyeron al éxito de la transición político significan hoy un obstáculo para la gobernabilidad democrática (Garretón, 1984; 1996; 2001; 2010; Natera, 2004).

Dentro del conjunto de las rigidices constitucionales señaladas el sistema electoral binominal ${ }^{8}$ es el que más restringe la expresión, organización y representación de facciones y corrientes de pensamiento emergentes en los partidos políticos y en la sociedad. La participación ciudadana aparece en este contexto como un instrumento despolitizado y manejado según los intereses partidistas estratégicos. Por añadidura, el enclaustramiento de la clase política es propio de las elites quienes asociada a su elevado estándar social concentran poder en muchos contextos. La Concertación creo estrechos círculos políticos que limitaron el acceso a los nuevos militantes y ciudadanos en la toma de decisiones (Andersson, Gordillo de Anda \& Laerhoven, 2008). Además, los partidos chilenos reproducen el sistema centralista del gobierno constituyendo un orden jerárquico interno que determina la toma de decisiones por los grupos dominantes de la cúpula concentrados en la capital del país con la consecuente marginalidad relativa de las bases de regiones. Los militantes jóvenes y de regiones así como todo actor externo a la burocracia estatal y a la elite política queda bastante 
excluidos. La gobernanza deviene auto centrada, marcada por disputas de interés de las elites partidarias, evidenciándose su escasa inclinación por compartir el poder político y el control sobre los recursos financieros con la gente local, gobiernos locales y al interior del mismo partido a menos que responda a estrategias políticas especificas (Fox, 2003;2006; Eaton, 2004ab; Andersson \& Laerhoven, 2008).

Los resultados del estudio ponen en evidencia la continuidad de las prácticas de concentración del poder por la clase política respecto al acceso de las nuevas generaciones militantes a los cargos públicos en el gobierno subnacional, tal como lo podemos observar en el siguiente testimonio:

El diputado Esteben fue muy duro al principio frente a esa situación [El entrevistado se refiere a la elección por concurso público de dos jóvenes militantes políticos como Secretarios Ministeriales]. Hubo una actitud tremenda de fuerte de los partidos a los que pertenecían, la elite partidaria quería que se saque al joven de la Secretaria Ministerial de Salud, quería que se saque al joven de la Secretaria Ministerial de Educación, que no se considerarán porque no eran militantes reconocidos. Se les había considerado porque fueron elegidos por concurso público, que estaba en la lógica de incorporar gente joven a la política, por lo menos se puso dos secretarios regionales por ese sistema. Se tuvo ese problema con los Partidos, muy fuerte, y finalmente se tuvo que sacar a ambos [Entrevistado $\mathrm{N}^{\circ} 18$ autoridad local mayor de 50 años]. [Los nombres propios fueron cambiados a fin de asegurar la anonimización de la información]

La generación de relevo ve restringido el acceso a los cargos públicos del gobierno subnacional controlados por las elites. Los resultados del estudio dan cuenta que tales situaciones no son excepcionales, lo excepcional fue más bien que estos jóvenes lograrán -sin la autorización de sus partidos- acceder a los cargos de los cuales fueron finalmente depuestos. La generación de relevo experimenta la situación como marginación del rol político mismo: no se sienten "verdaderos políticos”.

En la administración pública muchos de nosotros que hemos sido dirigentes, nos hemos visto imposibilitados de acceder a los cargos públicos, o sea, un dirigente, tiene que llegar hasta ser dirigente ¡no más, si esto es para los políticosi Nos han de alguna manera coartado (Entrevistado N52, militante menor de 40 años).

Más allá del prestigio y la envestidura es la jerarquía de los cargos públicos que logra negociar el militante, todos capitalizados por la oligarquía partidista, que indica la posición de "político” en el campo. La relación entre la posición dentro del partido y el gobierno es evidente, numerosos secretarios generales de partidos políticos devienen presidentes y ministros de gobierno. En regiones las menores oportunidades laborales y económicas exacerban la lucha por los cargos que significan acceso a las redes de influencias y de oportunidades económicas. 


\section{La crítica de la generación de relevo a los partidos políticos}

La importancia de la representación social es interpretada de manera distinta por la generación de recambio y las elites, dando cuenta de la impronta histórica identitaria en la visión de la política de las distintas generaciones.

Mientras que para la elite la omisión y postergación de la disidencia ideológica fue fundamental en el consenso político que los llevo al éxito de la transición democrática para la generación de relevo constituyen : prácticas antidemocráticas de reproducción del poder de las elites que privilegian los intereses electorales y económicos por sobre las demandas ciudadanas y que ponen el riesgo el prestigio de los partidos y el sentido mismo de la política que, para ellos es la representación ciudadana.

La generación de recambio y líderes sociales nos habla desde dentro y desde fuera de los partidos, de incorruptibles alianzas entre los poderes políticos y económicos para mantener el estatus quo de las elites, coincidiendo con las observaciones de Serani (2006).

Es tan poderoso el tema económico con el político, que tú no tienes a quién representar. Es decir, nosotros ¿qué discusión tenemos respecto a la legalización de marihuana? No tenemos. ¿El aborto? ¿La eutanasia?: los temas que quiere escuchar la gente. ¿El tema del matrimonio homosexual? ¿Qué opinamos sobre las concentraciones económicas? ¡Si los nuestros y los otros están dirigiendo el tema! Son parte de eso. ¿Qué opinamos de eso? ¡No podemos opinar nada! Claro, tenemos el bastión de las instituciones religiosas que nos censuran, que nos tiene ahí, jah! Entonces cualquier cosa que digamos sobre esto, va el llamado de atención, va el partido. El partido ya no representa a nadie, ni en el mundo, ni acá [Entrevistado $\mathrm{N}^{\circ} 29$ funcionario público menor de cuarenta años].

Las significan como alianzas conservadoras resistentes, salvo honrosas excepciones, al acceso de un espectro más amplio de militantes y ciudadanos a los partidos políticos y al gobierno subnacional. Encaran a la "vieja guardia" el quiebre generacional al interior de sus partidos, su cinismo y oportunismo político. Convergen en la crítica con líderes de la sociedad civil que se muestran reacios a cualquier forma institucionalizada de poder, incluidos los partidos políticos.

La política queda fuera de la organización estudiantil. Mientras más apolítico sea el dirigente, más bien visto es. Porque si es militante, ya viene marcado. Lamentablemente o afortunadamente para mi caso, los partidos de la Concertación no han definido estrategia para el movimiento estudiantil. Entonces sus dirigentes han tenido bastante libertad, lo que no paso con los pingüinos, porque los partidos de la 
Concertación además de ser gobierno apretaron un poco a los pingüinos. Esta vez fue a la inversa, tuvimos que ir a las reuniones de los partidos para que se enteraran de lo que estaba pasando, que quienes eran los ultra, los reformistas porque la vieja guardia no entendía bien. Uno de ellos me decía " a ver Diego, si yo digo eh... Si yo digo becas, ¿me lo van a aceptar los ultras? No.- ¿pero porque si las becas es gratuidad? - Sí, pero las becas es un subsidio a la demanda y los estudiantes está pidiendo subsidio a la oferta, que el estado financia sus universidad y que no ande repartiendo voucher. Entonces ellos no entendían estos matices (P2 dirigente estudiantil militante, menor de treinta años).

Es interesante notar como esta convergencia ideológica da cuenta de una cercanía generacional entre lideres sociales y militantes que desborda la identidad partidista y los une paradojalmente en el distanciamiento hacia los partidos políticos.

\section{La sociedad civil y la generación de relevo: coaptación y adaptación}

Comparamos en esta sección las visiones de la generación de relevo y de la elite respecto a la crisis de representatividad que atraviesan los partidos políticos de la Concertación. Observamos que mientras que la elite exterioriza las causas de la crisis la generación de relevo apunta hacia las prácticas políticas del establishment. En efecto, la elite explica la crisis de representatividad a partir de la apatía de las nuevas generaciones, herederas de la represión de la dictadura militar que le restó referentes formativos de participación social. En este contexto, nos hablan con nostalgia de las décadas anteriores al advenimiento a la democracia en que la política tenía "un espíritu social" y un proyecto de sociedad democrática compartido, contrariamente al individualismo y falta de orientaciones de las organizaciones sociales actuales marcadas por la impronta individualista neoliberal.

Si bien reconocen las generaciones que los preceden como activa y técnicamente mejor preparada cuestionan su falta de altruismo y la pertinencia de las causas sociales. Distinguen, particularmente a sus delfines como personas que se abocan a causas sociales "subterráneas" que no se condicen necesariamente con los temas-país prioritarios. Debilidad que atribuyen a que no vivieron, como ellos mismos, situaciones extremas en las cuales de la capacidad de consenso dependía el triunfo de la democracia en el país. Salvo excepciones, los ven como políticos de bajo perfil que no logran mayor influencia en sus colectividades ni en instancias locales de toma de decisiones debido entre otros factores, a sus escasas competencias negociadoras, y dificultades para ponderar lo fundamental de lo accesorio. La elite asocia a la generación de relevo a estrategias políticos confrontacionales producto de su desorientación respecto al verdadero sentido de la política. 
Identifican a generación de relevo como los “winners” (ganadores), o "carreristas" cuya política pragmática desestiman. Lo anterior también porque las nuevas generaciones superponen la política con su inserción laboral. En efecto, tanto la generación de relevo como los dirigentes de organizaciones sociales, participan en la creación de ONG y/o consultoras. Sus prácticas de gestión emulan las de la empresa, emplean tecnología informática yendo a la par con los procesos de modernización.

En resumen, la generación de relevo sitúa las causas de la crisis de representación de los partidos políticos en los vicios del campo que exacerba sus intereses en desmedro de la representatividad social. La elite en enfatiza el problema en el contexto socio político histórico que deprimió a la ciudadanía y promovió el individualismo. Ambas generaciones asumen la crisis de representatividad de los partidos políticos, pero esta representa claramente mayor interés para la generación en estudio. En lo que sigue, precisaremos la crítica de los últimos hacia la coaptación política de las organizaciones sociales y su reacción frente al fenómeno.

Según la generación de relevo, el sector tradicional de la sociedad civil emula la segmentación partidaria y lógica de reproducción del poder de las elites resultando de esta dinámica un progresivo distanciamiento de las bases sociales. Entendemos por sociedad civil tradicional aquella, conformada de organizaciones territoriales y funcionales formales con estructura organizacional verticalista, demandas monotemáticas acotadas a micro territorios y orientadas hacia la captación de recursos sociales. La generación de relevo tiene menos contacto con este grupo debido a que prevalecen alianzas anteriores con las elites partidistas; existe una importante distancia generacional y se diferenciación a nivel de las prácticas políticas. Los militantes con carreras en proceso de consolidación indican que son organizaciones promovidas “desde fuera”, desde las redes sociales del gobierno y los partidos políticos donde, se confunden las nomenclaturas de "beneficiarios" y de "clientes” de los partidos. Serían, en sus palabras: “organizaciones que también funcionan pero que no funcionan", ya que estarían vacías de socios y propuestas de desarrollo. Las elites partidistas mantendrían con la sociedad civil tradicional una relación clientelar basada en la reciprocidad político electoral y/o los intereses personales. El clientelismo referido - entre partidos y organizaciones sociales, en contraposición al que vincula a personas entre sí - se le denomina nuevo clientelismo (GarcíaGuadilla, 2002).

La generación de relevo reacciona frente al encerramiento del campo político y la coaptación de la sociedad civil tradicional adscribiéndose a las lógicas de la sociedad civil emergente y desafiando por lo mismo las formas tradicionales de hacer política. La nueva sociedad civil es aquel sector segmentado, activo y exigente de colectivos convocados por demandas emergentes que corresponden a la traslación de las sociedades contemporáneas desde las grandes utopías a reivindicaciones culturales localizadas territorialmente pero proyectadas globalmente (Giddens, 1991; 1999; 2002; 2004 Hopenhayn, 2007). Se abocan a problemáticas que no repre- 
sentan mayor interés para las elites a menos que se presenten bajo urgentes coyunturas políticas. Nos referimos a temas tan variados tales como, a saber: la defensa y conservación del medio ambiente; la promoción de la vida sana - deporte y consecución de vías ciclables-; comercio justo ; arte; voluntariado - un techo para Chile, Servicio País-; equidad de género; aborto terapéutico, etc.

Participan de la nueva sociedad civil son mayoritariamente jóvenes y adultos jóvenes, más educados - técnicos y profesionales- que la sociedad civil tradicional. Ellos impresionan a los políticos experimentados como empoderados y bien informados de sus derechos.

El dirigente nuevo que es más impulsivo, el tipo que sabe sus derechos, que está más estudiado, que en algunos casos tiene un grado de conocimiento profesional, ya sea un título técnico profesional que haya sacado. Ellos están en una parada distinta, son más jóvenes, y van consiguiendo sus objetivos a través de entrevistas, de ser incisivos, de usar mucho los medios de comunicación porque saben que eso sensibiliza también a las autoridades y las autoridades no quieren estar en contra de grupos sociales.(...) Los dirigentes son tipos súper jóvenes, algunos ingenieros, otros medioambientalistas, y se la juegan y van a todas. Han hecho bastantes cosas acá, mediáticas, tienen 10.000 firmas mínimo para el movimiento de Achibueno [Entrevistado N54, menor de 40 años].

Conocen muy bien las reglamentaciones y espacios que se le otorgan a la ciudadanía en materias de políticas, programas y proyectos de desarrollo. Comparten con la generación de relevo el interés por los aspectos técnicos de la política lo que expresan como “estar bien preparados”. Consecuentemente se invierten en el estudio jurídico y administrativos de sus distintos dominios de interés, a saber; legislatura de los gobiernos subnacionales, reglamentos de las organizaciones sociales, bases de los proyectos, programas y políticas participación de las organizaciones sociales, ley y reformas de la educación. Situación que confirma planteamientos de autores que asocian la mayor cultura política a la estructura de clase, eventualmente a la aparición de una clase media políticamente moderada (Fukuyama, 1999; Inglehart, 1989; Andersson \& Laerhoven 2007).

Priman en la nueva sociedad civil relaciones horizontales, des localizadas territorialmente, con menores grados de estructuración y formalidad, cuya estructura emerge en la contingencia de los acontecimientos que la convocan haciéndola indeterminada e inasible para las tradicionales prácticas de coaptación partidistas (García-Huadilla, 2002). Prefieren la participación política de audiencia, la transversalidad de las alianzas, la despartidización y la autonomía (Hopenhayn, 2007). Su visión del gobierno y de la sociedad se encuentra aún en gestación y no cuentan con propuestas de cambio social consolidadas, sino más bien con un conjunto de reivindicaciones yuxtapuestas que favorecen la autonomía ideológica. 
Los más jóvenes de la generación de relevo plantean, que su rol frente a la nueva sociedad civil es de acompañamiento y asesoría, ofrecer su capital político versus el rol de dirigencia y de persuasión ideológica que ha caracterizado la relación entre la elite y la sociedad civil tradicional.

Creo que la conducta de uno dice mucho y tenemos que ser capaces de transparentarnos a nosotros mismos, transparentarnos hacia la comunidad. Mientras la comunidad nos vea haciendo cosas por ellos, nos vea en todos lados, creo que vamos a recuperar la confianza que hemos perdido, que es bien importante. Esto no pasa por un tema de corrupción-no corrupción, no pasa por un tema de apitutamiento. Pasa por un tema de confianza y de priorizar los intereses colectivos por sobre los intereses individuales que nos están haciendo bastante daño [Entrevistado $N^{\circ} 56$, funcionario público, menor de 40 años].

A cambio, de manera involuntaria, la nueva sociedad civil "viva" les ofrece referentes alternativos para pensar y hacer política.

\section{Nuevas lógicas: mediatización, transversalidad y territorio}

La generación de relevo y la nueva sociedad civil convergen en nuevas lógicas políticas: la mediatización de la política; la transversalidad de las alianzas y la importancia del territorio.

Las nuevas generaciones de políticos transitan junto con la nueva sociedad civil desde una noción de democracia de partidos políticos a una de democracia de audiencia que se adecua mejor a las prácticas y características de la nueva sociedad civil (Dalton, Scarrow \& Bruce 2004). Construyen una imagen mediática - "sociedad vitrina" - empleando estrategias diversas y flexibles de expresión y presión - medios de comunicación escritos, radiales, informáticos, espectáculos artísticos, - que amplían el espectro de actores. Sus colectivos buscan no sólo ser escuchados por las autoridades, sino que sobre todo sensibilizar a un público más joven, educado, informado y de mejor condición económica que la ciudadanía en general. La clase política en busca de legitimación se ve presionada a ampliar el espacio público y considerar las corrientes de opinión de estos grupos (Bherer, 2010).

Las prácticas referidas confirman los estudios de Bherer, respecto a las tendencias relacionales políticas modernas que los distinguen de las prácticas basadas en acuerdos cara a cara de las elites partidistas de Sin embargo es importante señalar que, al menos en el contexto regional en que nos situamos, coexisten ambas estrategias, la tendencia es hacia la flexibilización y complementariedad de las mismas.

La transversalidad, en el contexto del estudio implica la asociación 
y/o establecimiento de alianzas con organizaciones y/o individuos de adscripciones o simpatías político partidarias contrarias sin mediar exigencias de exclusividad. Prima una lógica plural de complementariedad de esfuerzos y poderes civiles en favor de las causas que persiguen. La generación de relevo puede hacer frente común con actores que no militan o con aquellos definidos como adversarios políticos por la vieja guardia, pero con quienes comparte intereses sociales, territoriales o ideológicos. Otra variante de la transversalidad en las alianzas, es un cambio de actitud hacia los empresarios con los cuales se establecen también alianzas instrumentales lo que supone superar la polaridad política tradicional de los partidos algunos militantes de centro o izquierda hacia este sector.

La transversalidad en las alianzas desborda el ámbito estratégico instrumental electoral constituyendo una reacción frente a un problema complejo con múltiples aristas.

Puede ser un PPD, un radical, un socialista, puede ser un independiente ¿por qué no? si el tipo es capaz, si se las sabe. Incluso un gallo de derecha ¿qué tiene? Si se tienen que mirar las capacidades. Y la gente de mi partido, los más tradicionales, los más antiguos me decía:”No puedes andar con uno de derecha”. Yo digo: mala suerte. La solución al problema va a beneficiar a toda la gente y para eso estamos. Si se da la posibilidad de que yo trabaje con él lo voy a hacer siempre [Entrevistado 35, militante menor de 40 años].

Esta línea denota una flexibilización de la clásica polarización partidista y de conglomerados de partidos, hacia la relativización de los referentes ideológicos. Sí bien, la transversalidad política no es exclusiva de las nuevas generaciones se distingue por estar sustentada en un discurso crítico frente a la ineficiencia política que resulta de las rigideces ideológicas de sus pares de edades más avanzadas. Esta apertura es favorecida por la sensibilidad que desarrollan los nuevos políticos frente a la endogamia de las elites resistentes a su propio liderazgo y renuentes frente a temáticas sociales vigentes de la sociedad chilena.

Para aquellos nuevos políticos con posturas claramente críticas, la transversalidad sería una reacción frente al relajo de los fundamentos identitarios que visualizan en sus propios conglomerados políticos. El razonamiento es el siguiente: las alianzas con opositores en post de una vinculación con la sociedad civil y la defensa de causas sociales comunes es, un mal menor si se compara con el trastoque de valores que resulta de la intervención de los poderes fácticos de las elites partidistas.

No se trata de un proceso de desideologización, entendida como la falta de un conjunto articulado de valores e ideas a través de las cuales se interpretan distintos fenómenos sociales. La tendencia es hacia la apartidización - apolítico- es decir, que la generación de recambio se distancia de un paradigma asociado a una institución formal y a las formas de reproducción del poder de los partidos políticos. La generación de relevo 
no cuestiona el sustrato ideológico de sus referentes sino que las estrategias implementadas. Tampoco, se puede hablar de facciones partidistas pues abarca al conjunto de partidos.

Un tercer elemento - sumado a la mediatización de la información y la transversalidad de las alianzas- que distingue las prácticas políticas de la generación de recambio y que potencia las alianzas trasversales es su vocación por las causas sociales arraigadas territorialmente que, les permiten levantar referentes políticos transversales con quienes se marginan del partidismo. La utopía de cambio social aun indeterminada se reconstituye en utopías fragmentadas que paradojalmente asientan y refuerza las identidades locales, pero que al mismo tiempo se deslocalizan del territorio y se proyectan - mediante el uso de las nuevas tecnologías de las comunicaciones- hacia lo global planetario (Beck \& Giddens 2002).

En los espacios locales -desde donde se proyectan las demandas a los niveles supra locales-, se potencia el capital social de la generación de recambio. Es decir, al momento en que la contingencia social demanda manifestaciones de cuerpo presente de los actores, emergen las intrincadas y superpuestas redes de relaciones familiares, privadas y las alianzas propias de las comunidades potenciando su capital político. La elite partidista no puede contrarrestarse a esta visibilidad mediática y social que podría significar eventualmente un re ordenamiento de las relaciones de poder del campo político a favor de la generación de recambio.

Las causas de raigambre territorial actúan como ejes que transcienden las pertenencias partidarias actuando como un denominador común que afianza la identidad y solidaridad entre los actores de los movimientos sociales. Este elemento es de suma importancia, si se asume que la sustentabilidad de las estrategias de participación requiere de una fuerte intersubjetividad, es decir, una serie de símbolos y significados compartidos que orientan y dan sentido a las acciones que emprenden (Bourdieu, 1980; 1994; 2001). El territorio provee a la nueva sociedad civil los referentes subjetivos de los cuales los partidos políticos y los esfuerzos de participación social del estado carecen.

En resumen la generación de relevo y la nueva sociedad civil comparten intereses y prácticas políticas - la mediatización, la tranversalidad y el territorio- lo que hace factible su vinculación mutua y desafía las prácticas políticas tradicionales. Sin embargo, la relación es compleja ya que por una parte la nueva sociedad civil es renuente a la instrumentalización política y por otra la generación de relevo se encuentra en los márgenes de sus propios campos políticos partidistas.

\section{Conclusiones}

Iniciamos el análisis de la generación de relevo en el campo político de los partidos de centro y de izquierda con el fin de comprender desde allí 
su visión de la crisis de representatividad de los respectivos partidos políticos y su potencial de representar a la nueva sociedad civil. Los partidos políticos deben enfrentar la coyuntura de representar a la nueva sociedad civil siempre y cuando adapten sus lógicas de reproducción del poder y cedan espacios a las nuevas generaciones de militantes y líderes sociales.

En efecto, la falta de renovación (encerramiento) del campo político y los vicios de las formas tradicionales de hacer política devienen escasamente representativas y deprimen el potencial de social de las nuevas generaciones de militantes. La generación de relevo se ubica en una posición marginal dentro del campo político lo que bloquea en parte importante su acceso al poder y favorece su adscripción a las lógicas políticas de los líderes de los nuevos movimientos sociales.

No obstante la generación de relevo tiene potencial de representación ya que se trata de una generación que representa, por una parte la continuidad de los partidos políticos - fueron socializados por sus fundadores y proyectan desde allí sus carreras - pero tienen la distancia crítica, cercanía generacional y vinculación suficiente con la nueva sociedad civil para transitar hacia nuevas prácticas políticas. La cercanía generacional relativa- debido al amplio rango de edad y diferentes itinerarios biográficos, sobre todo para los que rodean la cuarentena- y el capital político heredado favorece esta adaptación. Comparten ambas generaciones una visión heterocrítica hacia la primacía de los intereses políticos por sobre el mandato ciudadano que domina el campo partidista, sin embargo esta generación enfrenta la resistencia de los nuevos líderes ciudadanos a la conducción partidista lo que los obliga a relativizar los referentes políticos en los cuales fueron formados por los fundadores de la Concertación.

Se establece una forma diferente de vinculación entre los partidos políticos y la ciudadanía cuyos límites e impacto, si bien son aún difusos deja vislumbrar algunas pistas:

Si bien, el protagonismo de la generación de relevo es tensionado por su posición fronteriza en el campo político y el rechazo de la nueva sociedad civil hacia la conducción partidista, se abre camino adaptándose a los códigos emergentes de la nueva sociedad civil, a saber: 1) la mediatización;2) transversalidad de las alianzas y la 3) importancia del territorio. Respecto a lo primero, la generación en estudio transita desde una política basada en las relaciones cara a cara hacia una de audiencia, que complementa la interacción cara a cara con las bases sociales en el territorio con estrategias informatizadas, más compleja y eficiente de difusión y organización. Lo segundo releva la compartimentación partidista cede a la transversalidad de las alianzas y la pluralidad de las causas en pos de potenciar los capitales (financiero, social y simbólico) de los actores de los movimientos sociales. La estructura social transversal de la nueva sociedad civil emerge en la contingencia y es difícil de capturar en su génesis y desarrollo, la generación de relevo opta entonces por integrarla y acompañarla aptándose progresivamente a sus prácticas organizacionales. Las for- 
mas tradicionales de reproducción del poder basadas que instrumentalizan a las organizaciones sociales tienden hacia una lógica de alianzas transversales que relativiza las compartimentaciones ideológicas y transita lentamente hacia la despartidización y la autonomía de la sociedad civil. El tercer eje, en el que se mueve la generación de relevo es el territorio que actúa como plataforma en la que objetiva y potencias las redes y el capital social, económico y político de los movimientos sociales y también demanda con fuerza la equidad "territorial” en el país que otrora no se realiza.

Orientación de la generación de relevo que por una parte, causa resistencias dentro del establishment al desafiar sus lógicas pero por otra, les es imposible restarse ya que constituye los escasos nexos que establecen con la nueva sociedad civil.

De mantenerse esta tendencia es posible que se creen nuevas reglas del juego que re configuren las relaciones de poder dentro del campo partidista en las que el mayor capital social será más que el prestigio político, la capacidad de establecer redes y hacer parte de la estructura simbólica de la nueva sociedad civil. Los partidos políticos que lideraron durante largo tiempo a la sociedad civil, por su coherencia con un sentido social, hoy no comprenden sus códigos, son cuestionados y la relación de fuerzas se revierte, la historia les ha pasado la cuenta, son estos quienes deben adaptarse a las nuevas reglas del juego de la sociedad civil. Puede que sea aun muy temprano para que se objetive este nuevo orden pero el proceso está en desarrollo, no sólo a través de la consiga del movimiento estudiantil: "el pueblo unido avanza sin partido" sino que también en la reflexión de quienes representan el futuro de los partidos políticos de la Concertación. 


\section{Notas}

${ }^{1}$ La investigación corresponde al Proyecto PSD- 60; Programa Bicentenario, Financiado por el CONICYT 2008-2012. Camino Lircay s/n Talca, Región del Río Maule.

${ }^{2}$ Se reproduce en este sentido, a nivel regional, la concentración del poder político en linajes que en Chile que según Tylor (1998) y Posner (2004) controlaban durante el período en que se realizaron los estudios más del $90 \%$ de los votos.

${ }^{3}$ La noción de generación se define a principios del siglo XIX, con indicadores biográficos que las clasifican en diferentes grupos etarios. El interés de estos estudios generacionales es la reproducción social, la superposición, coincidencia y coexistencia entre generaciones (Ortega y Gasset, [1923]; Mannheim, [1928]). Las corrientes críticas de los años 1960, reactivas al conservadurismo que dominaba hasta entonces en las ciencias sociales realizan un viraje desde en interés de la reproducción social hacia la influencia, desde perspectivas comprensivas, del contexto socio cultural e interacción social en el cambio y conflicto generacional (Feuer, 1968; Mendel 1969). El desarrollo posterior de la noción ha significado la complejización del fenómeno vía la integración de las condiciones estructurales y subjetivas tales como la identidad social

${ }^{4}$ En Chile, las edades promedio de la clase política de la Concertación es bastante avanzada ya que corresponden a la generación que fue protagonista de los sucesos históricos que marcaron un punto de inflexión en la historia nacional, es decir durante el gobierno de la Unidad Popular de Salvador Allende y el posterior Golpe de estado.

${ }^{5}$ Excluimos en componente étnico de la noción de etclase que se origina en los estudios antropológicos de los procesos de aculturación de inmigrantes y grupos étnicos.

${ }^{6}$ Concepto acuñado por Ortega y Gasset [1923].

${ }^{7}$ El período de la transición se caracteriza por un fuerte estado unitario; un sistema electoral binominal; voto voluntario; un senado que permite que una minoría tenga incluso poder sobre la presidencia y la ausencia de mecanismos de participación de la sociedad civil que en su gran mayoría prevalecen hasta el día de hoy (Garretón, 2010).

${ }^{8}$ El sistema binominal de la Constitución Política de 1980 regula el sistema electoral condicionando la elección de los candidatos a las dos grandes coaliciones partidistas, la “Concertación de Partidos por la Democracia” (representante de la centro izquierda) y de la derecha o” Alianza para el Progreso” (Garretón, 2010:129-134; Siavelis, 1997). 


\section{Bibliografía}

Andersson, K., Gordillo de Anda, G. \& Van Laerhoven, F. (2008), Decentralization and Rural Development: Local Governance Lessons from Latin America, University of Arizona Press, Arizona.

Arellano, R. \& Bravo, C. (2006), "Desarrollo sin ciudadanos: el "modelo" chileno de los últimos veinte años", en Crisis y Renovación de los Partidos Políticos, Biblioteca del Congreso Nacional de Chile, Santiago de Chile, pp. 275-298.

Beck, A. \& Giddens, S. (2002), Reflexive modernization: politics, tradition and aesthetics in the moedern social order, Ulrich Lash Stanford University Press, Stanford. Disponible en: http://www,bibliovault,org/ BV,book,epl?BookId=667

Bherer, L. (2010), "Successful and Unsuccessful Participatory Arrangements: Why is There a Participatory Movement at the Local Level?”, Journal of Urban Affairs, vol.32, n.2, pp.287-303.

Boeninger, E. (1993) “La gobernabilidad. Un concepto multidimensional”, Revista Estudios Internacionales, Universidad de Chile, Santiago de Chile, n.105, pp.79-94.

Ídem (1998), Democracia en Chile. Lecciones para la gobernabilidad, Andrés Bello, Santiago de Chile.

Bourdieu, P. (1980), Le sens pratique, [1930-2002], Minuit, Paris.

Ídem (1994), Raisons pratiques, Sur la théorie de l'action, Raisons d'agir, Paris.

Ídem (2001), Science de la science et réflexivité, Raisons d'agir, Paris.

Ídem (2000), Campo Político, Presses Universitaires de Lyon, Lyon, pp.35.

Cavallo, A. (1992), Los hombres de la transición. Santiago: Editorial Grijalbo.

Ídem (1998), La historia oculta de la transición, Grijalbo, Santiago de Chile.

Dalton, R., Scarrow, S. \& Bruce C. (2004), "Democracy Transformed?: Expanding Political Opportunities in Advanced Industrial Democracies", Journal of Democracy, vol.15, n.1, pp.124-138.

Eaton, K. (2004a), Politics Beyond the Capital. The Design of Subnational Institutions in South America, Stanford University Press, Stanford. [Links] 
Ídem (2004b), "Risky Business: Decentralization from Above in Chile and Uruguay”, Comparative Politics, vol.37,n.1, pp.1-22. [Links]

Feuer, L. (1968), The Conflict of Generations, Heinemann, London.

Fox, J. (2006), “Sociedad civil y políticas de rendición de cuentas”, Perfiles Latinoamericanos, n.27 (enero-junio de 2006), Flacso, México, pp. 33-68.

Fox, J. \& Brooks, D. (2003), Cross-Border Dialogues, US Social, México.

Fukuyama, F. (1999) Social Capital and Civil Society, The Institut of Piblic Policy. Disponible en : http://www.imf.org/external/pubs/ft/seminar/1999/ reforms/fukuyama.htm

García-Guadilla, M. (2002), "Democracy, Decentralization and Clientelism: New Relationships and Old Practices", Latin American Perspective, n.29 (5), pp.90-109.

García Ojeda, M. (2011), "Capital social y clientelismo: otra limitación para el control social " Polis (Santiago), n.10, pp. 123-146.

Garretón, MA. (1984) Dictaduras y Democratización, Flacso. Santiago de Chile.

Ídem (1995), Hacia una nueva era política: Estudio sobre las democratizaciones, Fondo de Cultura Económica, Santiago de Chile.

Ídem (2001), "Popular Mobilization and the Military Regime in Chile”. En: Power and PopularProtest: Latin American Social Movements. S. Eckstein (Ed.), University of California Press, Berkeley.

Garretón, MA. y Garretón, R. (2010), “La democracia incompleta en Chile: La realidad tras los rankings internacionales”, Revista de Ciencia Política, Santiago de Chile, vol.30, n.1, pp.115-148.

Giddens, A. (2004), People Out of Place: Globalization and the Citizenship Gap, (Co-Ed. Gershon Shafir), Routledge Press, New York.

Ídem (2002), Economics and Political Science, Centre for the Study of Global Governance Oxford University-London School, Oxford, pp.404.

Ídem (1991), Modernity and Self-Identity.Self and Society in the Late Modern Age, Polity, Cambridge.

Ídem (1999), The Consequences of Modernity, Polity, Cambridge.

Glaser, B. \& Strauss, A. (1967), The discovery of grounded theory, Aldine, Chicago. 
Habermas, J. (1992), "Further Reflections on the Public Sphere”, en C. Calhoun (Ed.), Habermas and the Public Sphere, Mass Press, Cambridge, pp.453.

Habermas, J. (1988), Ensayos políticos, Península, Barcelona.

Ídem (1986), Problemas de legitimación en el capitalismo tardío, Amorrotu, Buenos Aires.

Hopenhayn, M. (2007), “La dimensión cultural de la ciudadanía social”, en Ciudadanía y Desarrollo Humano Cuaderno de Gobernabilidad Democrática. F. C. (Coor), Siglo XXI, Buenos Aires, pp. 169-200.

Inglehart, R. (1997), Modernization and Postmodernization, Princeton University Press, Princeton.

Leccardi, C. \& Feixa, C. (2011), “El Concepto De Generación en Las Teorías Sobre La Juventud”, Última Década, n.34, Cidpa, Valparaíso, Junio, pp.11-32.

Manheim, Karl [1928], “Das Problem der Generationen”, Traducido como “El problema de las generaciones”, Revista Española de Investigaciones sociológicas, n.62, 1993, pp, 193-242, a partir de la versión inglesa de 1952 ["On the Problem of Generations”, incluida en K, Manheim, Essays on the Sociology of Knowledge, pp, 276-322, Routledge; nueva versión, con prefacio de Bryan S, Turner, [1992], n.37.

Mardones, R. (2008), “Descentralización: una definición y una evaluación de la agenda legislativa chilena (1990-2008)”, Revista Eure, XXXIV, n.102, pp.39-60.

Ídem (2006), “Descentralización y Transición en Chile”, Revista de Ciencia Política de la Pontificia Universidad Católica, vol.26, n.001, pp.3-24.

Mascareño, A. (2009), “Medios Simbólicamente Generalizados y el Problema de la Emergencia Cinta de Moebio”, Revista Electrónica de Epistemología de Ciencias Sociales, n.36, pp.197.

Mendel, G. (1969), La crisis de las generaciones, Península [1972], Barcelona.

Natera, A. (2004), “La noción de gobernanza como gestión pública participativa reticular”, Documentos de Trabajo Política y Gestión, Departamento de Ciencia Política y Sociología, Universidad Carlos III, Madrid.

Ídem (2001), El liderazgo político en la sociedad democrática, Centro de Estudios Políticos y Constitucionales, Madrid. 
OCDE: Organisation for Economic Cooperation and Development (2009), Estudios Territoriales de la OCDE Chile, Ministerio del Interior, Santiago de Chile.

Ídem (2010), Revisión Económica Chile, Ministerio del Interior, Santiago de Chile.

O'Neill, K. (2005), Decentralizing the State: Elections, Parties, and Local Power in the Andes, Cambridge University Press, New York.

Ídem (2003), “Decentralization as an Electoral Strategy”, Comparative Political Studies, vol.36, n.9, pp.1068-1091.

Ortega y Gasset, J. [1923], “La idea de las generaciones” (Primera parte de El tema de nuestro tiempo), en Obras Completas, III, pp. 145-156, Alianza, 2005 (edición citada como Ortega [1938]), Madrid.

Ídem [1933], I, “Idea de las generaciones”, $3^{\text {a }}$ lección, II, “De nuevo, la idea de generación”, 5a lección, en Entorno a Galileo (1550-1650), Ideas sobre las generaciones decisivas en la evolución del pensamiento europeo, Esquema de las crisis, Revista de Occidente, 1942 y 1956, Alianza, 1994, (Obras Completas).

Otano, R. (1995), Crónica de la transición, Planeta, Santiago de Chile.

Posner, P. (2004), "Local Democracy and the Transformation of Popular Participation in Chile”, Latin American Politics and Society, vol. 46, n. 3, pp. 55-81

Rancière, J. (2006), Política, policía, democracia, LOM, Santiago de Chile.

Ídem (1996), El desacuerdo, Nueva Visión, Buenos Aires.

Rawls, J. (1971), Teoría de la Justicia, Cuarta reimpresión, Fondo de Cultura Económica, Ciudad de México.

Rosanvallon, P. (2008), La légitimité démocratique, Impartialité, réflexivité, proximité, Seuil, Paris.

Ídem (2006), La contre-démocratie. La politique à l'âge de la défiance, Seuil, Paris.

Saffiro, E. (2004), “Desafíos a la democracia”, Desafíos Democráticos, LOM Ediciones, Santiago de Chile.

Serani (2006), “Crisis y Renovación de los partidos políticos”, Serie de Estudios,Biblioteca del Congreso Nacional de Chile, Santiago de Chile, pp. 1-37. Disponible en : www,bcn,cl/bibliodigital/pbcn/estudios/ estudios_pdf./nro08-06,pdf 
Siavelis, P. (1997), “Chile: las relaciones entre el poder ejecutivo y el poder legislativo después de Pinochet”, [versión revisada y actualizada del artículo en inglés: "Executive-legislative relations in post-Pinochet Chile: A Preliminary Assessment”], en Scott Mainwaring y Matthew Shugart (Ed.) (1997), Presidentialism and Democracy in Latin America, University Press, Cambridge.

Ídem (2004), “Sistema electoral, desintegración de coaliciones y democracia en Chile: ¿El fin de la concertación?”, Revista de Ciencia Política, Centeno (eds,)Universidad Católica Cardenal Raúl Silva Henríquez, Santiago de Chile, vol.24, n.1, pp.58-80,

Strauss, A. (1987), Qualitative analysis for social scientist. Cambridge University Press, New York.

Strauss, A. \& Corbin, J. (1990), Basics of qualitative research, Sage. London.

Tironi, E. (1987), "Marginalidad, movimientos sociales y democracia”, Revista Perspectivas, Sur Investigadores, Santiago de Chile, n.14, pp. 3223.

Ídem (1997), La transición democrática, Dolmen, Santiago de Chile.

Ídem (1999a), La irrupción de las masas y el malestar de las elites, Grijalbo, Santiago de Chile.

Tironi, E. \& Agüero, F. (1999b), “¿Sobrevivirá el nuevo paisaje político chileno?”, Revista Estudios Públicos, Centro de Estudios Públicos, Santiago de Chile, n.74, pp.151-168.

Taylor, L. (1998) Citizenship, Participation, and Democracy: Changing Dynamics in Chile and Argentina, St. Martin's Press, New York.

Whittingham, MV. (2002), “Aportes de la teoría y la praxis para la nueva gobernanza”, en VII Congreso Internacional del CLAD sobre la Reforma del Estado y de la Administración Pública, CLAD, Lisboa.

Zemelman, H. (1992), Horizontes de la Razón Historia y necesidad de utopía I, Anthropos, Barcelona. 